\title{
Pregnancy-related anxiety and its associated factors during COVID-19 pandemic in Iranian pregnant women: a web-based cross-sectional study
}

Zeinab Hamzehgardeshi ${ }^{1}$, Shabnam Omidvar ${ }^{2}$, Arman Asadi Amoli ${ }^{3}$ and Mojgan Firouzbakht ${ }^{*}$

\begin{abstract}
Background: Pregnancy is a risk factor for coronavirus disease 2019 (COVID-19). Pregnant women suffer from varying levels of pregnancy-related anxiety (PRA) which can negatively affect pregnancy outcomes. The aim of this study was to assess PRA and its associated factors during the COVID-19 pandemic.

Methods: This web-based cross-sectional study was conducted in 2020 on 318 pregnant women purposively recruited from primary healthcare centers in Sari and Amol, Iran. Data were collected using questionnaires (PRAQ, Edinburg, KAP of COVID-19, CDA-Q and Demographic questionnaire), which were provided to participants through the social media or were completed for them over telephone. Data were analyzed with the linear regression and the logistic regression analysis, at the significance level of 0.05 using the SPSS software (v. 21).

Results: Around 21\% of participants had PRA, 42.1\% had depression, and 4.4\% had COVID-19 anxiety. The significant predictors of PRA were number of pregnancies $(P=0.008)$, practice regarding COVID-19 $(P<0.001)$, COVID-19 anxiety $(P<0.001)$, depression $(P<0.001)$, and social support $(P=0.025)$ which explained $19 \%$ of the total variance. Depression and COVID-19 anxiety increased the odds of PRA by respectively four times and 13\%, while good practice regarding COVID-19 decreased the odds by $62 \%$.

Conclusion: Around 21\% of pregnant women suffer from PRA during the COVID-19 pandemic and the significant predictors of PRA during the pandemic include number of pregnancies, practice regarding COVID-19, COVID-19 anxiety, depression, and social support. These findings can be used to develop appropriate strategies for the management of mental health problems during pregnancy in the COVID-19 pandemic.
\end{abstract}

Keywords: Coronavirus disease 2019, Pandemic, Pregnancy-related anxiety

\footnotetext{
* Correspondence: Firouzbakht_m@yahoo.com; mfirozbakht@baboliau.ac.ir ${ }^{4}$ Department of Nursing- Midwifery, Comprehensive Health Research Center, Babol Branch, Isalamic Azad University, Babol, Iran

Full list of author information is available at the end of the article
}

C C The Author(s). 2021 Open Access This article is licensed under a Creative Commons Attribution 4.0 International License, which permits use, sharing, adaptation, distribution and reproduction in any medium or format, as long as you give appropriate credit to the original author(s) and the source, provide a link to the Creative Commons licence, and indicate if changes were made. The images or other third party material in this article are included in the article's Creative Commons licence, unless indicated otherwise in a credit line to the material. If material is not included in the article's Creative Commons licence and your intended use is not permitted by statutory regulation or exceeds the permitted use, you will need to obtain permission directly from the copyright holder. To view a copy of this licence, visit http://creativecommons.org/licenses/by/4.0/. The Creative Commons Public Domain Dedication waiver (http://creativecommons.org/publicdomain/zero/1.0/) applies to the data made available in this article, unless otherwise stated in a credit line to the data. 


\section{Background}

Pregnancy is among the most important events in women's life. It is associated with many different physical, emotional, and social changes [1]. Besides, pregnant women are concerned with fetal growth and their future responsibilities and hence, are prone to varying levels of psychological problems such as mood changes, fatigue, emotional disorders, mixed anxiety-depressive disorder, and pregnancy-related anxiety (PRA) [2]. PRA is a common problem among women during and after pregnancy [3].

PRA is defined as concerns, preoccupations, and fears related to pregnancy, delivery, neonatal health, and childrearing [4]. Anxiety is a normal response in stressful conditions [5]. Accordingly, healthy levels of PRA help pregnant women adhere to health-related recommendations [6]. However, severe PRA can negatively affect women's physical and mental health and their children's cognitive, emotional, and behavioral development [2]. Different studies reported the relationship of PRA with health-related problems such as intrauterine growth restriction [7], premature birth [8], cleft lip and palate, still birth, neonatal death [9], autism, hyperactivity, and neurodevelopmental disorders [10]. The prevalence of PRA in developing countries is $10-25 \%$ [11]. Studies in Iran assessed PRA using general anxiety questionnaires and reported prevalence rates of 32.5 and $40 \%$ [12, 13].

A major source of PRA is affliction by infectious diseases [14], particularly during epidemics and pandemics. Pandemics affect people and communities at different levels and cause disturbances in communities. They challenge psychological resilience and are usually associated with horror, stress, anxiety, sleep disorders, and negative attitudes towards health [5]. Previous studies reported that affliction by viral infections during the epidemics of H1N1 influenza, Middle East Respiratory syndrome (MERS), and Severe Acute Respiratory Syndrome (SARS) caused pregnant women negative clinical outcomes such as death, spontaneous abortion, premature birth, and fetal death $[15,16]$.

Coronavirus disease 2019 (COVID-19) was first observed in December 2019 in Wuhan, China, and rapidly spread throughout the world [17]. In January 2020, the World Health Organization introduced it as an international crisis [18]. In Iran, COVID-19 was first reported in February and then, it affected many people around the country. The Ministry of Health of Iran reported that by the middle of October 2020, the number of patients with COVID-19 and the number of its associated deaths in Iran were more than 935,000 and 47,000, respectively (http://ird.behdasht.gov.ir/2020.28.11). This study was conducted during the first peak of COVID 19 outbreak, when little information was available about the disease and ways of spread of COVID - 19 in population, and there was no extensive studies about the disease. There was any definitive treatment or any vaccine against the COVID-19 [19].

The risk factors for COVID-19 include impaired immunity, history of respiratory or cardiac disorders, cancer, aging, obesity, and pregnancy [6, 20]. However, there are little information about effect of COVID-19 in pregnancy [21], Pregnancy-related physiologic changes in the anatomy and the function of the lungs together with impaired immunity put pregnant women at great risk for affliction by COVID-19 [17]. During epidemics and pandemics, factors such as fear over affliction and death and disturbances in daily activities due to the necessity of quarantining cause varying levels of anxiety [17]. Uncertainties over transmission routes and doubts about national readiness for pandemic management affect people's adherence to preventive measures and cause them psychological strains [22, 23]. The sources of concern and anxiety for pregnant women during pandemics include concern over quarantine-related loneliness during and after delivery, limited access to healthcare services due to fear over affliction, increased requests for delivery through elective Cesarean section, concerns related to the frequent use of disinfectants, and concerns over child care, breastfeeding, and vaccination [24].

A recent study on 178 pregnant women in Italy during the COVID-19 pandemic reported that $46.6 \%$ of them had anxiety due to their fear over potential fetal anomalies caused by COVID-19, 65\% of them had fear over intrauterine growth restriction, and $51 \%$ of them had fear over premature birth [5]. Studies during the MERS pandemic also showed that $80 \%$ of afflicted patients experienced fear $[25,26]$, isolation, social stigmatization, anxiety and anger during the two-week course of quarantine period [26].

To the best of our knowledge, limited studies have assessed PRA during the COVID-19 pandemic and no study has yet assessed it during the pandemic using PRA-specific questionnaires. Therefore, the present study was conducted to address this gap. The aim of the study was to assess PRA and its associated factors during the COVID-19 pandemic.

\section{Methods \\ Design}

This web-based cross-sectional descriptive-correlational study was conducted from April 17 to May 31, 2020.

\section{Participants}

Study population comprised all pregnant women referred to primary healthcare centers in Amol and Sari, 
Iran. Inclusion criteria were having a healthy pregnancy without history of COVID - 19 disease, access to social media or telephone, no history of stressful life events in the past 6 months (including divorce, marriage, or significant loss), no affliction by mental health disorders, and no intake of psychiatric medications. The only exclusion criterion was voluntary withdrawal from the study. Sampling was performed purposively.

The pergnant women who were included in the study had a complete health file in primary health care centers. For sampling, we referred to primary healthcare centers in Amol and Sari, Iran, and created a list of eligible women and their telephone numbers. Then, midwives in the study setting called eligible women over telephone, invited them to the study, provided them with the study instruments over the WhatsApp application, and asked them to complete them. Study instruments for participants with no access to the WhatsApp application were completed through telephone-based interviews. In order to have confidential questionnaire, one of the researchers (AAA) filled them by information obtained through the telephone interviews.

Based on the rule of thumb of fifteen participants per item [27], as the PRAQ has seventeen items, sample size was calculated to be 300 .

\section{Instruments}

Study instruments were a demographic and midwifery characteristics questionnaire, the Edinburgh Postnatal Depression Scale, the Pregnancy Related Anxiety Questionnaire, the Corona Disease Anxiety Questionnaire, and a COVID-19 knowledge, attitude, and practice questionnaire. The questionnaire was in Persian.

The demographic and midwifery characteristics questionnaire included items on age, educational level, place of residence, occupation, level of family support, financial status, pregnancy wantedness, number of pregnancies, route of previous deliveries, and history of abortion, premature birth, bleeding during pregnancy, gestational diabetes mellitus, hypertension, and placental disorders.

The Edinburgh Postnatal Depression Scale is used for depression assessment during pregnancy and after delivery [28]. It contains ten multiple-choice questions on depression severity scored $0-3$ (items 1,2 , and 4 ) or $3-0$ (items 3 and 5-10). The total score of the scale is $0-30$ and respondent with scores more than 12.5 are considered to have depression [29]. A former study reported the acceptable validity of this scale [30].

The Pregnancy Related Anxiety Questionnaire assesses pregnancy-related fears and concerns [31]. The short form of this questionnaire has seventeen items scored on a seven-point scale from 1 ("Definitely not true") to 7 ("Definitely true"). The possible total score of the questionnaire is $17-119$ with higher scores indicating greater anxiety. There is no cutoff point for the score of this questionnaire, while people with scores ranging from 65 to $70 \%$ total scores considered to have anxiety [32]. In the present study, scores greater than 66.3 were interpreted as anxiety. This questionnaire has acceptable validity and reliability [31].

The COVID-19 knowledge, attitude, and practice questionnaire was a researcher-made questionnaire developed based on the protocols recommended by the World Health Organization and the Ministry of Health of Iran for COVID-19 prevention and management. The knowledge part of this questionnaire had thirteen items on the transmission routes and the methods for the prevention and management of COVID-19.The knowledge items were about the signs and symptoms of the COVID - 19, prevention of the COVID - 19, transmission of the COVID- 19 virus from mother to child during pregnancy, lactation during disease and treatment of the COVID - 19). Items were scored either zero ("No" or "I don't know") or 1 ("Yes), resulting in a possible total score of 0-13. Scores greater than 9 were interpreted as good knowledge about COVID-19. The attitude part of the questionnaire had two items on the controllability of the COVID-19 pandemic which were scored either zero ("Disagree" or "I don't know") or 1 ("Agree"). Therefore, the possible total score of the attitude part is $0-2$ and score 2 shows good attitude. The practice part included three items on the use of gloves and facemask in outdoor areas and attendance at public places during the COVID-19 pandemic. Items were scored either zero ("Yes") or 1 ("No"), resulting in a possible total score of 0-3 with score 3 showing good practice. The validity of this questionnaire was assessed through face and content validity assessments. Eleven experts rated the items, and the content validity indices (CVI) of the three parts of the questionnaire were calculated to be $0.81-1$. The Cronbach's alpha of the questionnaire was 0.79 .

The Corona Disease Anxiety Questionnaire (CDA-Q) was developed in Iran with eighteen items on physical and mental anxiety. Items are scored on a four-point scale as follows: zero: "Never"; 1: "Sometimes"; 2: "Mostly"; and 3: "Always". The possible total score of this question is $0-54$ and respondents with scores greater than 37.8 are considered to have anxiety. This questionnaire has acceptable validity and reliability [33].

\section{Data analysis}

Data were analyzed using the SPSS software (v. 21.0). The measures of descriptive statistics were used for data description, while the linear regression analyses were used to determine the predictors of PRA. The logistic regression analyses were used to odd ratio of PRA. Since there were many variables in the study (City, Health Center, Age, Education, Residence, job, Husband job, 
Social support, Gravid, Abortion, Pre-term labor, Pain, Vaginal delivery, any medical history, Knowledge, Attitude, Practice, PRAQ, CDA-Q, Depression), variables which had relationship with PRA at a significance level of less than 0.2 were entered in the regression models. Data were analyzed at the significance level of 0.05 .

\section{Results}

During the two-month course of data collection, the study instrument was viewed 942 times and 318 pregnant women completed them (response rate: 53\%). The mean of response time was $16 \mathrm{~min}$ and $96 \%$ of participants completed the instruments via the WhatsApp application. The flow chart participants' recruitment showed in the Fig. 1.

The mean of participants' age was $28.57 \pm 5.06$ years and most of them had university degree (54.7\%), were housewife (85.5\%), lived in urban areas (67\%), were primiparous (59.7\%), and had good social support (50.6\%) (Table 1).

The mean scores of participants' knowledge, attitudes, and practice regarding the COVID-19 pandemic were respectively $9.17 \pm 2.02$ (in the possible range of $0-13$ ), $0.95 \pm 0.86$ (in the possible range of $0-2$ ), and $2.59 \pm 0.63$ (in the possible range of 0-3). Moreover, the mean scores of their PRA, depression, and COVID-19 anxiety were respectively $44.64 \pm 19.93$ (in the possible range of 17-119), $12.16 \pm 3.43$ (in the possible range of $6-24$ ), and $10.58 \pm$
8.51 (in the possible range of $0-45$ ) (Table 2). Most participants had limited knowledge (53.1\%), poor attitude (65.1\%), and poor practice (66.7\%) respecting COVID-19. Moreover, $20.8 \%$ of them had PRA, $42.1 \%$ had depression, and $4.4 \%$ had COVID-19 anxiety (Table 2).

Linear regression analysis using the stepwise method showed that the significant predictors of PRA were number of pregnancies $(P=0.008)$, practice regarding COVID-19 $(P<0.001)$, COVID-19 anxiety $(P<0.001)$, depression $(P<0.001)$, and social support $(P=0.025)$. These variables explained $19 \%$ of the total variance of PRA mean score (Table 3).

The logistic regression analysis also showed that the number of pregnancies (one vs. more), history of serious health problems (diabetes mellitus, renal disease, and hypertension vs. others or none), knowledge (score above 9) and practice respecting COVID-19 (good vs. poor), and COVID-19 anxiety (yes vs. no) were eligible variables for logistic regression analysis. The results of the analysis showed that depression increased the odds of PRA by four times (adjusted odds ratio: 4.298, 95\% confidence interval: $2.161-8.546, P<0.001)$ and COVID19 anxiety increased the odds of PRA by $13 \%$ (adjusted odds ratio: 1.125, 95\% confidence interval: 1.066-1.187, $P<0.001)$. Good practice respecting COVID-19 also decreased the odds of PRA by $62 \%$ (adjusted odds ratio: 0.379, 95\% confidence interval: $0.188-0.765, P<0.001$ ) (Table 4).

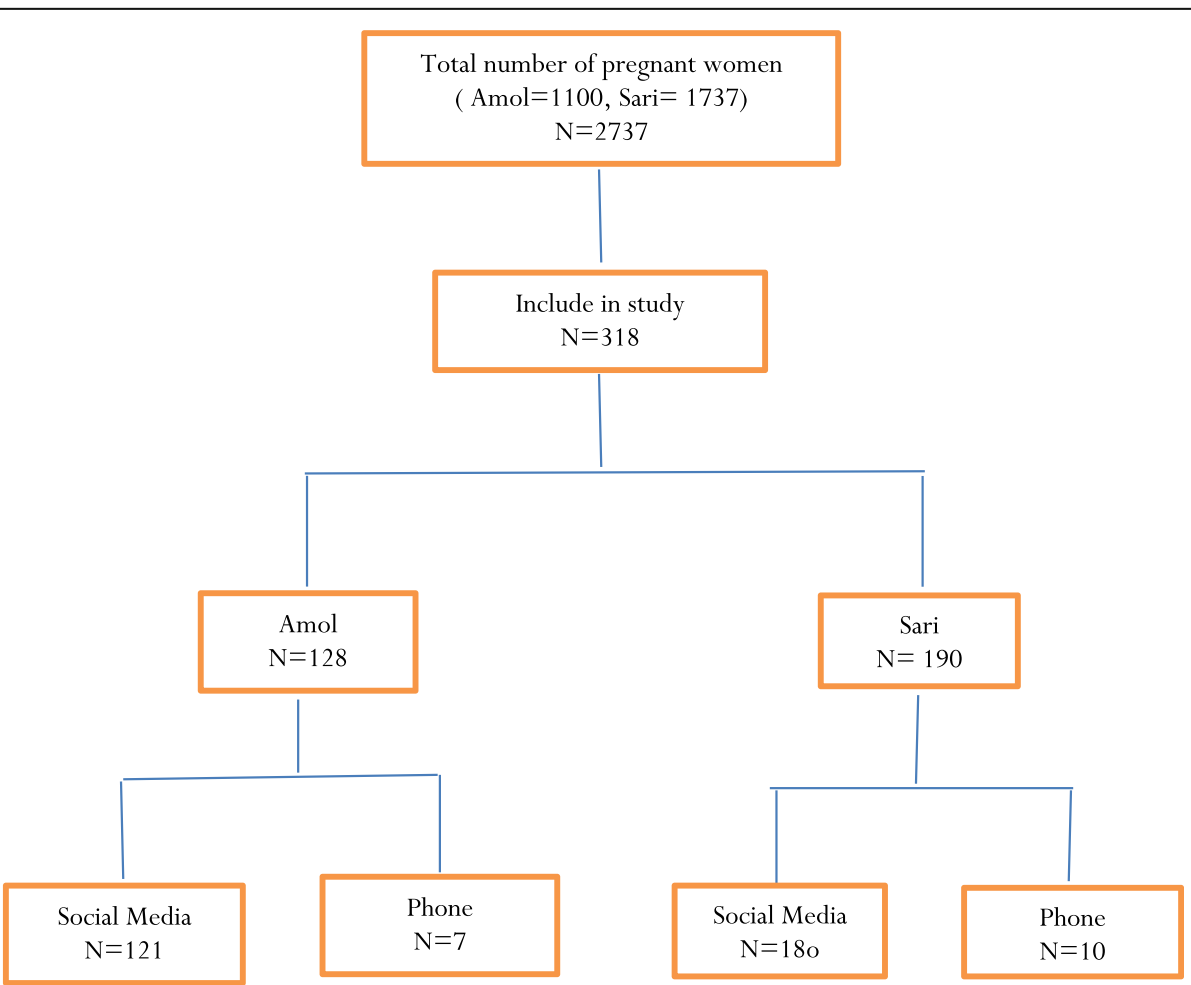

Fig. 1 Flow chart of study 
Table 1 Participants' demographic and midwifery characteristics

\begin{tabular}{|c|c|}
\hline Characteristics & Mean \pm SD or $\mathrm{N}(\%)$ \\
\hline Age (Years) & $28.57 \pm 5.06$ \\
\hline \multicolumn{2}{|l|}{ Educational level } \\
\hline Below diploma & $32(10.1)$ \\
\hline Diploma & 112(35.2) \\
\hline University & $174(54.7)$ \\
\hline \multicolumn{2}{|l|}{ Occupation } \\
\hline Employed & $46(14.5)$ \\
\hline Housewife & $272(85.5)$ \\
\hline \multicolumn{2}{|l|}{ Place of residence } \\
\hline Rural areas & 105(33) \\
\hline Urban areas & $213(67)$ \\
\hline \multicolumn{2}{|l|}{ Husband's occupation } \\
\hline Health-related fields & $20(6.3)$ \\
\hline Other & 268(84.3) \\
\hline Unemployed & $30(9.4)$ \\
\hline \multicolumn{2}{|l|}{ Social support } \\
\hline Good & 161(50.6) \\
\hline Moderate & $142(44.7)$ \\
\hline Poor & $15(4.7)$ \\
\hline \multicolumn{2}{|l|}{ Number of pregnancies } \\
\hline 1 & 190(59.7) \\
\hline 2 & 100(31.4) \\
\hline 3 & $174(54.7)$ \\
\hline \multicolumn{2}{|l|}{ History of abortion } \\
\hline Yes & 75(23.6) \\
\hline No & 243(76.4) \\
\hline \multicolumn{2}{|c|}{ History of premature delivery } \\
\hline Yes & $9(2.8)$ \\
\hline No & 309(97.2) \\
\hline \multicolumn{2}{|c|}{ History of bleeding during pregnancy } \\
\hline Yes & $44(13.8)$ \\
\hline No & $274(86.2)$ \\
\hline \multicolumn{2}{|l|}{ History of pain } \\
\hline Yes & $83(26.1)$ \\
\hline No & 235(73.9) \\
\hline \multicolumn{2}{|c|}{ History of serious health problems } \\
\hline Yes & $32(10.4)$ \\
\hline No & 295(81.4) \\
\hline
\end{tabular}

\section{Discussion}

This study aimed to assess PRA and its predictors during the COVID-19 pandemic. Findings showed that almost $21 \%$ of the participants experienced PRA. This is in line with the findings of a former study in Iran [34]. In a systematic review a prevalence of anxiety was reported from 3.8 to $17.5 \%$ in Asian countries [35] .A study in China also showed that the prevalence of moderate to severe PRA was 28.8\% [36]. The COVID-19 pandemic has reduced pregnant women's access to routine prenatal care services due to factors such as rapid spread of the disease, lack of an effective treatment or vaccine, the necessity of quarantining and its subsequent loneliness during affliction, stigmatization and despair [37], and concerns over contamination with the virus in healthcare settings [11]. Moreover, it has caused pregnant women different psychological disorders due to the restriction of the number of companions in healthcare settings, concerns over the lack of workforce in maternity settings, limited access to specialized care services for women with suspected COVID-19 [38], and requests for pregnancy termination or elective Cesarean section surgery [39].

Findings showed that pregnant women with COVID19 anxiety were $13 \%$ more likely to have PRA. Moreover, those with diabetes mellitus, renal disease, or hypertension were 3.6 times more at risk for PRA. Contrarily, participants with good practice respecting COVID-19 were $62 \%$ less likely to have PRA. These findings imply that the COVID-19 pandemic is a serious challenge for pregnant women. A former study in Iran also showed that pregnant women had higher levels of COVID-19 anxiety compared with their non-pregnant counterparts [40]. Another study in Iran revealed that pregnant women in the third trimester of pregnancy were concerned with COVID-19 disease and its consequences and had higher levels of anxiety. That study also reported that higher levels of anxiety among pregnant women during the COVID-19 pandemic might be due to their limited access to healthcare services, their concerns over the unsafe environment of healthcare settings, and concerns over affliction by the disease [34]. A study in Pakistan showed that $84 \%$ of pregnant women had fear over COVID-19 and the mean score of generalized anxiety disorder among women with fear over COVID19 was significantly higher [41].

Our findings also showed the number of pregnancies as a significant predictor of PRA. Similarly, a former study found gravidity as a significant factor contributing to PRA symptoms and reported that nulliparous women had higher levels of PRA compared with their multiparous counterparts [42]. Moreover, we found that most participants had poor knowledge, attitude, and practice respecting COVID-19. Attitude and practice respecting COVID-19 are correlated with the level of knowledge $[10,43,44]$. Moreover, our findings showed that $42 \%$ of participants had depression. In a systematic review study the prevalence of depression was reported from 5.2 to $40 \%$ [35]. COVID-19 prevention largely depends on social distancing and quarantining [45] which in turn can 
Table $\mathbf{2}$ The mean scores of the main study outcomes

\begin{tabular}{|c|c|c|c|c|}
\hline Outcomes & Mean \pm SD & Range & Level & N (\%) \\
\hline \multirow[t]{2}{*}{ Knowledge regarding COVID-19 } & $9.17 \pm 2.02$ & $0-13$ & Poor & $169(53.1)$ \\
\hline & & & Good & 149(46.9) \\
\hline \multirow[t]{2}{*}{ Attitude regarding COVID-19 } & $0.86 \pm 0.95$ & $0-2$ & Poor & $207(65.1)$ \\
\hline & & & Good & $111(34.9)$ \\
\hline \multirow[t]{2}{*}{ Practice regarding COVID-19 } & $0.63 \pm 2.59$ & $0-3$ & Poor & 106(33.3) \\
\hline & & & Good & $212(66.7)$ \\
\hline \multirow[t]{2}{*}{ PRA } & $19.93 \pm 44.64$ & $17-119$ & Yes & $66(20.8)$ \\
\hline & & & No & 252(79.2) \\
\hline \multirow[t]{2}{*}{ Depression } & $3.43 \pm 12.16$ & $6-24$ & Yes & 184(42.1) \\
\hline & & & No & 134(57.9) \\
\hline \multirow[t]{2}{*}{ COVID-19 anxiety } & $8.51 \pm 10.58$ & $0-45$ & Yes & $14(4.4)$ \\
\hline & & & No & 304(95.6) \\
\hline
\end{tabular}

cause social isolation, sadness, worries, anger, irritability, despair [46] and increasing level of domestic violence [35]. Studies on the general population in China reported that almost one third of them had depressive symptoms [47] and women had higher levels of depression and anxiety [18]. A study also showed that depressive symptoms have increased during the COVID-19 pandemic [42]. Anxiety and depression during the perinatal period are associated with depression in later years of life [48]. Moreover, PRA can increase the risk of antenatal depression [49] and pregnancy-related complications such as preterm birth [50]. Contrary to our findings, a former study reported no significant difference in depression rate among pregnant women before and after the SARS outbreak [8]. A study in Iran also showed no significant difference among non-pregnant, pregnant, and breastfeeding women regarding depression rate during the COVID-19 pandemic [40].

\section{Strengths and limitations}

One of the main strengths of the present study was webbased sampling and data collection which helped us collect the necessary data without exposing participants to COVID-19. However, web-based data collection can increase the risk of biases [51]. For instance, as people with better socioeconomic status may have better access to social media, web-based data collection may be associated with some levels of selection bias. We attempted to prevent and manage this bias through telephone-based data collection from participants with limited access to social media. There is a data collection limitation. Data collection through telephone may also associate with bias at data assessor level. As the total number of participants that completed the questionnaire via telephone were 17 person, it didn't seem to affect the results of the study. This study was done in a cross-sectional mode that does not show any causal relationship between variables.

Table 3 The results of linear regression analysis for PRA prediction

\begin{tabular}{|c|c|c|c|c|c|c|c|c|c|c|c|c|}
\hline & \multicolumn{6}{|c|}{ Model $^{a}$} & \multicolumn{6}{|c|}{ Model $2^{b}$} \\
\hline & \multirow[t]{2}{*}{ B } & \multicolumn{2}{|l|}{$95 \% \mathrm{Cl}$} & \multirow{2}{*}{$\begin{array}{l}P \text { - } \\
\text { value }\end{array}$} & \multirow[t]{2}{*}{$\mathrm{R}^{2}$} & \multirow[t]{2}{*}{$A R^{2}$} & \multirow[t]{2}{*}{$\bar{B}$} & \multicolumn{2}{|l|}{$95 \% \mathrm{Cl}$} & \multirow{2}{*}{$\begin{array}{l}P \\
\text { value }\end{array}$} & \multirow[t]{2}{*}{$\mathrm{R}^{2}$} & \multirow[t]{2}{*}{$\overline{A R^{2}}$} \\
\hline & & $\mathrm{LL}$ & UL & & & & & $\overline{\mathrm{LL}}$ & UL & & & \\
\hline Age & 0.048 & -0.232 & 0.613 & 0.376 & 41.6 & 38.2 & & & & & 19.8 & 18.7 \\
\hline Place of residence & 0.077 & -0.724 & 7.232 & 0.108 & & & & & & & & \\
\hline Occupation & 0.005 & -5.091 & 5.682 & 0.913 & & & & & & & & \\
\hline Number of pregnancies & -0.166 & -8.568 & -1.627 & 0.004 & & & -0.120 & -6.404 & -0.980 & 0/008 & & \\
\hline Social support & 0.101 & 0.119 & 6.806 & 0.042 & & & 0.101 & 0.434 & 6.503 & 0.025 & & \\
\hline Covid-19 anxiety & 0.410 & 0.737 & 1.202 & $<0.001$ & & & 0.415 & 0.754 & 1.209 & $<0.001$ & & \\
\hline Depression & 0.228 & 0.752 & 1.898 & $<0.001$ & & & 0.218 & 0.707 & 1.814 & $<0.001$ & & \\
\hline Knowledge regarding COVID-19 & -0.004 & $-0 / 969$ & 0.896 & 0.939 & & & & & & & & \\
\hline Practice regarding COVID-19 & -0.180 & -8.54 & -2.777 & $<0.001$ & & & -0.177 & -8.367 & -2.790 & $<0.001$ & & \\
\hline Attitude regarding COVID-19 & -0.028 & -2.733 & 1.456 & 0.549 & & & & & & & & \\
\hline
\end{tabular}


Table 4 The results of logistic regression analysis to determine the odds of PRA

\begin{tabular}{|c|c|c|c|c|c|c|}
\hline & & B & $P$ - value & AOR & $95 \% \mathrm{C}$ & \\
\hline & & & & & $\overline{\mathrm{LL}}$ & UL \\
\hline Number of pregnancies & 1 & 0.775 & 0.246 & 2.170 & 0.586 & 8.042 \\
\hline & $>1$ & & & & & \\
\hline Practice regarding COVID-19 & (score above 2) Good & -0.969 & 0.007 & 0.379 & 0.188 & 0.765 \\
\hline & $\begin{array}{l}\text { (score under 2) } \\
\text { Poor }\end{array}$ & & & & & \\
\hline Knowledge about COVID-19 & $\begin{array}{l}\text { (score above 9) } \\
\text { Good }\end{array}$ & $\begin{array}{l}-0.085 \\
\text { Ref. }\end{array}$ & 0.482 & 0.919 & 0.725 & 1.164 \\
\hline & $\begin{array}{l}\text { (score under 9) } \\
\text { Poor }\end{array}$ & & & & & \\
\hline COVID-19 anxiety & $\begin{array}{l}\text { (score above 37.8) } \\
\text { Yes }\end{array}$ & $\begin{array}{l}0.118 \\
\text { Ref }\end{array}$ & $<0.001$ & 1.125 & 1.066 & 1.187 \\
\hline & $\begin{array}{l}\text { (score under 37.8) } \\
\text { No }\end{array}$ & & & & & \\
\hline Depression & $\begin{array}{l}\text { (score abov12.5) } \\
\text { Yes }\end{array}$ & 1.458 & $<0.001$ & 4.298 & 2.161 & 8.546 \\
\hline & (score under 12.5) No & Ref & & & & \\
\hline History of health problems & $\begin{array}{l}\text { Yes (Diabetes mellitus, } \\
\text { hypertension, renal disease) }\end{array}$ & $\begin{array}{l}1.286 \\
\text { Ref }\end{array}$ & 0.055 & 3.617 & 0.971 & 13.480041 \\
\hline & No or others & & & & & \\
\hline constant & & -2.247 & 0.1 & 0.084 & & \\
\hline
\end{tabular}

\section{Conclusion}

This study shows that around 21\% of pregnant women suffer from PRA during the COVID-19 pandemic and the significant predictors of PRA during the pandemic include number of pregnancies, practice regarding COVID-19, COVID-19 anxiety, depression, and social support. Although the effects of COVID-19 on pregnancy outcomes are still unknown, COVID-19 can negatively affect pregnancy outcomes through causing different mental health problems such as anxiety. Lack of definitive treatment of COVID-19, limited information on the effect of the disease on pregnant mother and neonate, uncertainty about how long the quarantine is to be in action, fear of attending hospital and health care centers were some reasons on anxiety during quarantine COVID-19.

\section{Implications}

Healthcare authorities can use the findings of the present study to accurately identify pregnant women who are at higher risk for PRA and employ strategies to reduce their PRA through improving their knowledge, attitude, and practice regarding pandemics.

\section{Abbreviations}

COVID-19: Coronavirus disease 2019; PRA: Pregnancy-related anxiety; MERS: Middle East Respiratory syndrome; SARS: Severe Acute Respiratory Syndrome; SPSS: Statistical Package for Social Sciences; SD: Standard Deviation; AOR: Adjusted Odd Ratio; Cl: Confidence Interval

\section{Acknowledgements}

The authors would like to thank deputy of research of Mazandaran university of medical sciences for supporting them to this study, and thanks all pregnant women who participated in the study as well as all midwives in the study setting who helped us in data collection.

\section{Authors' contributions}

$\mathrm{ZH}$ and MF: study conception and design. MF, ZH and SO: Analysis and interpretation of data. ZH, MF, SO and AAA: Drafting of manuscript. ZH, MF, SO and AAA: Critical revision. All authors read and approved the final manuscript.

\section{Funding}

This study funded by vice chancellor of research and technology Mazandaran University of Medical Sciences.

\section{Availability of data and materials}

The datasets analyzed during the current study are available from the corresponding author on reasonable request.

\section{Declarations}

Ethics approval and consent to participate

The Ethics Committee of Mazandaran University of Medical Sciences, Sari, Iran, approved this study (code: IR.MAZUMS.REC.1399.7390). We confirm all methods were performed in accordance with the relevant guidelines and regulations. We confirm that written informed consent for study participations and all the explanations were displayed in the first page of the questionnaire. Questionnaires were anonymous.

Consent for publication

Not applicable.

Competing interests

The authors declare that they have no competing interests. 


\section{Author details}

'Department of Reproductive Health and Midwifery, Sexual and Reproductive Health Research Center, School of Nursing and Midwifery, Mazandaran University of Medical Sciences, Sari, Iran. ${ }^{2}$ Social Determinants of Health Research Center, Health Research Institute, Babol University of Medical Sciences, Babol, Iran. ${ }^{3}$ Commette Student Research, Babol University of Medical Sciences, Babol, Iran. ${ }^{4}$ Department of Nursing- Midwifery, Comprehensive Health Research Center, Babol Branch, Isalamic Azad University, Babol, Iran.

\section{Received: 9 December 2020 Accepted: 3 March 2021} Published online: 15 March 2021

\section{References}

1. Ahmadi A, Moosavi Sahebalzamani S, Ghavami F, Shafiee Y, Fathi AA. Effects of psychological interventions on postpartum depression, anxiety and infants' weight in primipara women. Prev Care Nurs Midwifery J. 2014;4(1): 19-31.

2. Bjelica A, Cetkovic N, Trninic-Pjevic A, Mladenovic-Segedi L. The phenomenon of pregnancy - a psychological view. Ginekol Pol. 2018;89(2): 102-6.

3. Chinchilla-Ochoa D, Peón PB-C, Farfán-Labonne BE, Garza-Morales S, LeffGelman P, Flores-Ramos M. Depressive symptoms in pregnant women with high trait and state anxiety during pregnancy and postpartum. Int J Women's Health. 2019;11:257.

4. Littleton $\mathrm{HL}$, Breitkopf $\mathrm{CR}$, Berenson $\mathrm{AB}$. Correlates of anxiety symptoms during pregnancy and association with perinatal outcomes: a meta-analysis. Am J Obstet Gynecol. 2007;196(5):424-32.

5. Mappa I, Distefano FA, Rizzo G. Effects of coronavirus 19 pandemic on maternal anxiety during pregnancy: a prospectic observational study. J Perinat Med. 2020;48(6):545-50.

6. Mirzadeh M, Khedmat L. Pregnant women in the exposure to COVID-19 infection outbreak: the unseen risk factors and preventive healthcare patterns. J Matern Fetal Neonatal Med. 2020:1-2.

7. Seyed Ahmadi Nejad FS, Golmakani N, Asghari Pour N, Shakeri MT. Effect of progressive muscle relaxation on depression, anxiety, and stress of primigravid women. Evid Based Care. 2015;5(1):67-76.

8. Loomans EM, Van Dijk AE, Vrijkotte TG, Van Eijsden M, Stronks K, Gemke RJ, et al. Psychosocial stress during pregnancy is related to adverse birth outcomes: results from a large multi-ethnic community-based birth cohort. Eur J Pub Health. 2013;23(3):485-91.

9. Fischbein RL, Nicholas L, Kingsbury DM, Falletta LM, Baughman KR, VanGeest J. State anxiety in pregnancies affected by obstetric complications: a systematic review. J Affect Disord. 2019;257:214-40.

10. Ranjan R, Ranjan GK. Knowledge regarding prevention of novel coronavirus (COVID-19): an electronic cross-sectional survey among selected rural community. Int J Trend Sci Res Dev. 2020;4(3):422-6.

11. Martini J, Petzoldt J, Einsle F, Beesdo-Baum K, Höfler M, Wittchen H-U. Risk factors and course patterns of anxiety and depressive disorders during pregnancy and after delivery: a prospective-longitudinal study. J Affect Disord. 2015;175:385-95

12. Zareipour M, Sadaghianifar A, Amirzehni J, Parsnezhad M, Ayuoghi RV. Exploring of depression, anxiety and stress in pregnant women referred to health centers of Urmia. Rahavard Salamat J. 2018;3(2):19-30.

13. Sadeghi N, Azizi S, Molaeinezhad M. Anxiety status in pregnant mothers at third trimester of pregnancy and its related factors in referrals to Bandar Abbas Hospitals in 2012. Iran J Obstet Gynecol Infertil. 2014;17(122):8-15.

14. Soto-Balbuena C, Rodriguez M, Escudero Gomis Al, Ferrer Barriendos FJ, Le $\mathrm{H}-\mathrm{N}, \mathrm{Pmb}-\mathrm{Huca} \mathrm{G}$. Incidence, prevalence and risk factors related to anxiety symptoms during pregnancy. Psicothema. 2018;30(3):257-63.

15. Huang C, Wang Y, Li X, Ren L, Zhao J, Hu Y, et al. Clinical features of patients infected with 2019 novel coronavirus in Wuhan, China. Lancet. 2020;395(10223):497-506.

16. Li Q, Guan X, Wu P, Wang X, Zhou L, Tong Y, et al. Early transmission dynamics in Wuhan, China, of novel coronavirus-infected pneumonia. N Engl J Med. 2020.

17. Haghdoost SM, Gol MK. The necessity of paying more attention to the neurological and psychological problems caused by COVID-19 pandemic during pregnancy. Int J Womens Health Reprod Sci 2020;8(3):243-244.

18. Wang C, Horby PW, Hayden FG, Gao GF. A novel coronavirus outbreak of global health concern. Lancet. 2020;395(10223):470-3.
19. Firouzbakht M, Omidvar S, Firouzbakht S, Asadi Amoli A. COVID-19 preventive behaviors and influencing factors in the Iranian population; a web-based survey. BMC Public Health. 2021;143:1-7.

20. Zheng Z, Peng F, Xu B, Zhao J, Liu H, Peng J, et al. Risk factors of critical \& mortal COVID-19 cases: A systematic literature review and metaanalysis. J Infect. 2020:81(2):e16-e25.

21. Zanardo V, Manghina V, Giliberti L, Vettore M, Severino L, Straface G. Psychological impact of COVID-19 quarantine measures in northeastern Italy on mothers in the immediate postpartum period. Int J Gynecol Obstet. 2020;150(2):184-8.

22. Kamate SK, Agrawal A, Chaudhary H, Singh K, Mishra P, Asawa K. Public knowledge, attitude and behavioural changes in an Indian population during the influenza a (H1N1) outbreak. J Infect Develop Countries. 2010; 4(01):007-14.

23. Al Najjar N, Attar L, Farahat F, Al TA. Psychobehavioural responses to the 2014 Middle East respiratory syndrome-novel corona virus [MERS CoV] among adults in two shopping malls in Jeddah, western Saudi Arabia. EMHJ-East Mediterr Health J. 2016;22(11):817-23.

24. Fakari FR, Simbar M. Coronavirus pandemic and worries during pregnancy; a letter to editor. Arch Acad Emerg Med. 2020;8(1):e21-e.

25. Lee D, Kim J, Kang H. The emotional distress and fear of contagion related to Middle East respiratory syndrome (MERS) on general public in Korea. Korean J Psychol Gen. 2016;35(2):355-83.

26. Jeong H, Yim HW, Song Y-J, Ki M, Min J-A, Cho J, et al. Mental health status of people isolated due to Middle East respiratory syndrome. Epidemiol Health. 2016;38.

27. Hair JF, Black WC, Babin BJ, Anderson RE, Tatham R. Multivariate Data Analysis: Pearson Education. New Jersey: Pretince Hall; 2016.

28. Cox JL, Holden JM, Sagovsky R. Detection of postnatal depression development of the 10-item Edinburgh postnatal depression scale. Br J Psychiatry. 1987;150(6):782-6.

29. Rasouli P, Shobeiri F, Cheraghi F, Rasouli R, Ghanbari V. Study of the relationship of anxiety and depression in third trimester pregnancy on growth index of neonates and preterm delivery. J Pediatr Nurs. 2016;2(4):1-9.

30. Ahmadi kani Golzar A, GoliZadeh Z. Validation of Edinburgh postpartum depression scale (EPDS) for screening postpartum depression in Iran. Iran J Psychiat Nurs. 2015:3(3):1-10

31. Van den Bergh PhD B. The influence of maternal emotions during pregnancy on fetal and neonatal behavior. J Prenatal Perinatal Psychol Health. 1990;5(2):119

32. Karamoozian M, Askarizadeh $\mathrm{G}$, Behroozi N. The study of psychometric properties of pregnancy related anxiety questionnaire. J Clin Nurs Midwifery. 2017;5(4):22-34

33. Alipour A, Ghadami A, Alipour Z, Abdollahzadeh H. Preliminary validation of the Corona disease anxiety scale (CDAS) in the Iranian sample; 2020.

34. Saadati N, Afshari P, Boostani H, Beheshtinasab M, Abedi P, Maraghi E. Health anxiety of pregnant women and its related factors during the pandemic of Corona virus: 2020.

35. Rahimi R, Dolatabadi Z, Moeindarbary S, Behzadfar S, Fakhr Ghasemi N, Tafrishi R, et al. A systematic review of the prevalence of mental health disorders in pregnant women during the COVID-19 pandemic. Int J Pediatr. 2020;8(11):12397-407.

36. Wang C, Pan R, Wan X, Tan Y, Xu L, Ho CS, et al. Immediate psychological responses and associated factors during the initial stage of the 2019 coronavirus disease (COVID-19) epidemic among the general population in China. Int J Environ Res Public Health. 2020;17(5):1729.

37. Shahyad S, Mohammadi MT. Psychological impacts of Covid-19 outbreak on mental health status of society individuals: a narrative review. J Mil Med. 2020;22(2):184-92

38. Jiang H, Jin L, Qian X, Xiong X, La X, Chen W, Yang X, Yang F, Zhang X, Abudukelimu N, Li X. Evidence of accessing antenatal care information via social media platforms supports mental wellbeing in COVID-19 epidemic. Bull World Health Organ. 2020.

39. Ding $X-X$, Wu Y-L, Xu S-J, Zhu R-P, Jia X-M, Zhang S-F, et al. Maternal anxiety during pregnancy and adverse birth outcomes: a systematic review and metaanalysis of prospective cohort studies. J Affect Disord. 2014;159:103-10.

40. Gharagozloo M, Sadatmahalleh SJ, Khomami MB, Moini A, Kazemnejad A. Mental health and marital satisfaction changes of pregnant and lactating women during the COVID-19 pandemic; 2020.

41. Hossain N, Samuel M, Sandeep R, Imtiaz S, Zaheer S. Perceptions, Generalized Anxiety and Fears of Pregnant women about Corona Virus infection in the heart of Pandemic; 2020. 
42. Lebel C, Mackinnon A, Bagshawe M, Tomfohr-Madsen L, Giesbrecht G Elevated depression and anxiety among pregnant individuals during the COVID-19 pandemic; 2020.

43. Zhong B-L, Luo W, Li H-M, Zhang Q-Q, Liu X-G, Li W-T, et al. Knowledge, attitudes, and practices towards COVID-19 among Chinese residents during the rapid rise period of the COVID-19 outbreak: a quick online crosssectional survey. Int J Biol Sci. 2020;16(10):1745.

44. Anikwe CC, Ogah CO, Anikwe IH, Okorochukwu BC, Ikeoha CC. Coronavirus disease 2019: knowledge, attitude, and practice of pregnant women in a tertiary hospital in Abakaliki, Southeast Nigeria. Int J Gynecol Obstet. 2020; 151(2):197-202.

45. Armitage R, Nellums LB. COVID-19 and the consequences of isolating the elderly. Lancet Public Health. 2020;5(5):e256.

46. Ren S-Y, Gao R-D, Chen Y-L. Fear can be more harmful than the severe acute respiratory syndrome coronavirus 2 in controlling the corona virus disease 2019 epidemic. World J Clin Cases. 2020;8(4):652.

47. Huang Y, Zhao N. Generalized anxiety disorder, depressive symptoms and sleep quality during COVID-19 outbreak in China: a web-based crosssectional survey. Psychiatry Res. 2020;288:112954.

48. Sutter-Dallay AL, Giaconne-Marcesche V, Glatigny-Dallay E, Verdoux H. Women with anxiety disorders during pregnancy are at increased risk of intense postnatal depressive symptoms: a prospective survey of the MATQUID cohort. Eur Psychiatry. 2004;19(8):459-63.

49. Rwakarema M, Premji SS, Nyanza EC, Riziki P, Palacios-Derflingher L. Antenatal depression is associated with pregnancy-related anxiety, partner relations, and wealth in women in northern Tanzania: a cross-sectional study. BMC Womens Health. 2015;15(1):68.

50. Brouwers EP, van Baar AL, Pop VJ. Does the Edinburgh postnatal depression scale measure anxiety? J Psychosom Res. 2001;51(5):659-63.

51. Kajdy A, Feduniw S, Ajdacka U, Modzelewski J, Baranowska B, Sys D, Pokropek A, Pawlicka P, Kaźmierczak M, Rabijewski M, Jasiak H. Risk factors for anxiety and depression among pregnant women during the COVID-19 pandemic: A web-based cross-sectional survey. Med. 2020;99(30):e21279.

\section{Publisher's Note}

Springer Nature remains neutral with regard to jurisdictional claims in published maps and institutional affiliations.

Ready to submit your research? Choose BMC and benefit from:

- fast, convenient online submission

- thorough peer review by experienced researchers in your field

- rapid publication on acceptance

- support for research data, including large and complex data types

- gold Open Access which fosters wider collaboration and increased citations

- maximum visibility for your research: over $100 \mathrm{M}$ website views per year

At $\mathrm{BMC}$, research is always in progress.

Learn more biomedcentral.com/submissions 